\title{
Dukungan Sosial Berhubungan Dengan Self-care Management Pada Lansia Hipertensi Di Puskesmas Sedayu II
}

\author{
Mahfud $^{1}$,Bari Barasila ${ }^{2}$,sofyan indrayana ${ }^{3}$ \\ ${ }^{1}$ Universitas Alma Ata Yogyakarta \\ 2 Program Studi Ilmu Keperawatan Universitas Alma Ata Yogyakarta \\ Telepon(0274) 434 2288,(0274) 4342270 kode pos 55184, \\ E-mail : uaa@almaata.ac.id
}

DOI: https://doi.org/10.33859/dksm.v10i2.463

\begin{abstract}
Abstrak
Latar Belakang :Dukungan sosial dapat meningkatkan pengetahuan dan menstabilkan emosional pada pasien hipertensi.Untuk menjaga dan mengatasi hipertensi pada lansia perlu dilakukan dukungan sosial dengan self-care managemen hipertensi.

Tujuan Penelitian : Tujuan penelitian ini bertujuan untuk mengetahui hubungan dukungan sosial dengan self-care manegement pada lansia hipertensi di Puskesmas Sedayu II Bantul Yogyakarta.

Penelitian ini merupakan penelitian kuantitatif dengan rancangan penelitian cross sectional. Populasi dalam penelitian ini adalah lansia di Puskesmas Sedayu II Kabupaten Bantul yang berjumlah 45 orang. Instrumen penelitian menggunakan kuesioner dukungan sosial dan kuisioner self-care management. Pengolahan data menggunakan uji statistik fisher's Exact Test.

Hasil penelitian : didapatkan bahwa dukungan sosial masuk dalam kategori baik yaitu 29 responden (70,7\%), sedangkan self-care management masuk dalam kategori baik yaitu 28 (69,3\%). Hasil penelitian diperoleh nilai dukungan sosial dengan self-care management hipertensi dengan $p=$ 0,000 dengan nilai keeratan hubungan koefisien korelasi $=0,514$ kategori sedang.

Kesimpulan: Ada hubungan antara dukungan sosial dengan self-care management pada lansia hipertensi di Puskesmas Sedayu II Bantul Yogyakarta dengan nilai signifikan 0,000 ( $<<00.5)$.
\end{abstract}

Kata Kunci : Dukungan sosial, self-care management, lansia hipertensi. 


\section{Abstract}

Background: Social support can increase knowledge and stabilize emotions in hypertensive patients. To maintain and overcome hypertension in the elderly, social support is needed by selfcare management of hypertension.

Research Objectives: The purpose of this study was to determine the relationship of social support with self-care management in elderly hypertension at the Public Health Center Sedayu II Bantul Yogyakarta. This research is a quantitative with design study a cross sectional.

The population in this study research were elderly in the Health Center Sedayu II Bantul amounting to 45 people. The research instrument used a social support questionnaire and a self-care management questionnaire. Processing data using the statistical test fisher's Exact Test.

Result: it was found that social support was in the good category of 29 respondents (70.7\%), while self-care management was in the good category of 28 (69.3\%). The results of the study obtained the value of social support with hypertension self-care management with $p=0,000$ with the closeness value of the correlation coefficient $=0.514$ medium category.

Conclusion: There is a relationship between social support and self-care management in elderly hypertension at the Public Health Center Sedayu II Bantul Yogyakarta with a significant value of

$0,000(p<00.5)$.

Keywords: Social support, self-care management, elderly hypertension.

\section{PENDAHULUAN}

Penyakit hipertensi menjadi permasalahan

kesehatan utama di Negara maju dan

Negara berkembang, hipertensi merupakan

penyakit yang tidak menular dan merupakan

penyebab kematian nomor satu secara global

Hipertensi menempati urutan pertama

dari 10 besar penyakit yang ada di Puskesmas

Kabupaten Bantul ditahun 2014. Sedangkan

pada tahun 2013 prevalensi hipertensi

didapatkan sebanyak 18.259 (8). salah satu

faktor yang memperparah terjadinya hipertensi

dikarenakan lansia kurangnya mendapatkan dukungan sosial dari keluarga, teman, masyarakat atau tetangganya sehingga selfcare manegement pada lansia tidak dilakukan dengan baik.

Untuk menjaga dan mengatasi hipertensi pada lansia perlu dilakukan dukungan sosial dengan Self-care Management hipertensi. Self-care Management merupakan suatu kemampuan seseorang dalam melakukan sesuatu secara mandiri, dalam melakukan aktivitas perawatan diri untuk mempertahankan kualitas hidup 
Dinamika Kesehatan Jurnal Kebidanan dan Keperawatan Vol 10 No. 22019 ( ISSN: 2086-3454 EISSN: 2549-4058) url: http://ojs.dinamikakesehatan.unism.ac.id DOI: https://doi.org/10.33859/dksm.v10i2

Dukungan Sosial Berhubungan Dengan Self-care Management Pada Lansia Hipertensi Di Puskesmas Sedayu II

individu, individu mampu meningkatkan dan memelihara kesehatannya sehingga tercapainya kesejahteraan tingkat kesehatan yang optimal (13).

Studi pendahuluan yang dilakukan melaluui wawancara di dapatkan data dari rekam medis Puskesmas Sedayu II, bahwa Kabupaten Bantul di Peskesmas Sedayu II kejadian hipertensi termasuk 10 besar penyakit tertinggi dan menduduki posisi pertama yaitu sebanyak 145 orang dengan prevalensi $13,13 \%$ pertahun. Prevalensi hipertensi di Puskesmas Sedayu II pada pasien Prolanis sebanyak 45 lansia hipertensi.

\section{BAHAN DAN METODE}

Penelitian ini adalah penelitian kuantitatif dengan rancangan penelitian cross sectional, rancangan cross sectional merupakan kegiatan mengumpulkan data pada suatu penelitian yang dilakukan dalam satu waktu secara bersamaan (39). Populasi dalam penelitian ini adalah lansia hipertensi yang berjumlah 45 orang di Puskesmas Sedayu II Bantul. Metode pengambilan sampel adalah nonprobability sampling dengan menggunakan teknik Purposive Sampling dengan pertimbangan kriteria insklusi dan ekslusi (41)

Analisa data menggunakan analisis univariat dan bivariat dengan uji Chi Square untuk mengetahui hubungan atau korelasi antara dua variabel yaitu dukungan sosial dan self-care management dengan skala nominal. variabel independen yaitu dukungan sosial dan variabel dependen yaitu Self-care Management (52)

Data primer meliputi kuesioner secara langsung pada lansia yang mengikuti Prolanis. Kuesioner dukungan sosial dan self-care management.

Kuesioner dukungan sosial dikembangkan oleh RAND Health dan disitasi oleh Prastyo (45) yang terdiri dari 5 pertanyaan dan 6 pilihan jawaban. Kuesiooner self-care management pasien hipertensi menggunakan kuesioner yang dikembangkan oleh Rosalind, M. Peters (46) dan disitasi oleh peneliti yang terdiri dari 10 pertanyaan dengan tujuh pilihan jawaban.

Kuesioner dukungan sosial alat ukur yang digunakan dalam penelitian ini adalah 
Dinamika Kesehatan Jurnal Kebidanan dan Keperawatan Vol 10 No. 22019 ( ISSN: 2086-3454 EISSN: 2549-4058)

url: http://ojs.dinamikakesehatan.unism.ac.id DOI: https://doi.org/10.33859/dksm.v10i2

Dukungan Sosial Berhubungan Dengan Self-care Management Pada Lansia Hipertensi Di Puskesmas Sedayu II

kuesioner dari yang terdiri dari 5 pertanyaan dan 6 pilihan jawaban. Hasil validitas kuesioner ialah 0,384 dan reliabilitas instrumen pengkuran dukungan sosial didapatkan nilai Cronbach's Alpha 0,740, semua item pertanyaan pengukuran dukungan sosial valid dan reliable

Kuesioner self-care management alat yang digunakan dalam penelitian ini adalah kuesioner yang terdiri dari 10 pertanyaan dengan tujuh pilihan jawaban. Hasil validitas kuesioner 0,393 sudah dinyatakan valid, dan reliabilitas instrumen pengkuran self-care management didapatkan nilai Cronbach's Alpha 0,807 terdapat satu pertanyaan pada instrumen yang tidak valid dan reliabel. Dari item pertanyaan yang tidak valid dan reliabel kemudian dilakukan perbaikan dengan content validity yaitu dengan meminta pendapat para pakar pada bidang yang sedang diteliti, sehingga semua item pertanyaan self-care management dinyatakan valid dan reliable.
HASIL DAN PEMBAHASAN

Tabel 1 Distribusi Responden menurut

Karakteristik pada Lansia di Puskesmas Sedayu II Bantul Yogyakarta

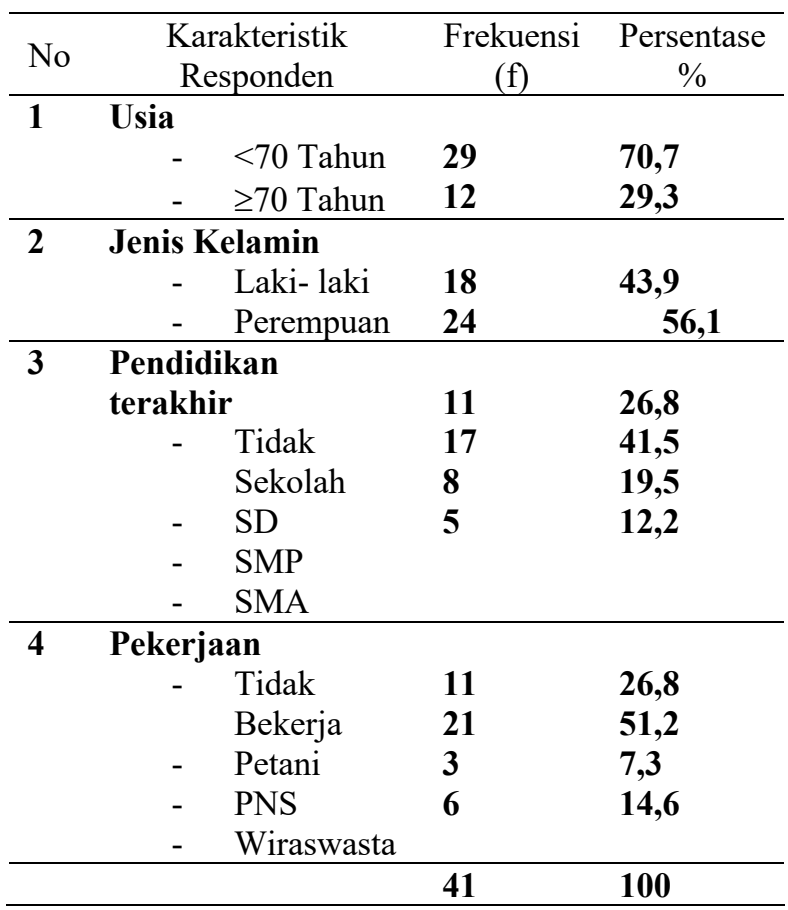

Berdasarkan Tabel 1 dapat dilihat distribusi responden berdasarkan usia menunjukkan bahwa responden paling banyak dengan usia $<70$ tahun sebanyak 29 responden $(70,7 \%)$. Menurut kategori jenis kelamin menunjukkan responden paling banyak berjenis kelamin perempuan yaitu sebanyak 23 responden (56,1\%). Menurut kategori tingkat pendidikan terakhir menunjukkan bahwa responden paling banyak dengan tamatan SD yaitu sebanyak 17 responden (41,5\%). Menurut kategori pekerjaan responden paling 
Dinamika Kesehatan Jurnal Kebidanan dan Keperawatan Vol 10 No. 2 2019 ( ISSN: 2086-3454 EISSN: 2549-4058) url: http://ojs.dinamikakesehatan.unism.ac.id DOI: https://doi.org/10.33859/dksm.v10i2

Dukungan Sosial Berhubungan Dengan Self-care Management Pada Lansia Hipertensi Di Puskesmas Sedayu II

banyak dengan kategori petani sebanyak 21

responden $(51,2 \%)$.

\section{Distribusi Frekuensi Dukungan Sosial}

Tabel 2 Distribusi Frekuensi Dukungan Sosial pada Lansia di Puskesmas Sedayu II Bantul Yogyakarta

\begin{tabular}{ccc}
\hline Dukungan Sosial & Frekuensi (f) & Persentase(\%) \\
\hline Kurang & 12 & 29,3 \\
\hline Baik & & 70,7 \\
\hline Total & 29 & $\mathbf{1 0 0}$ \\
\hline
\end{tabular}

Sumber: Data Primer 2018

Berdasarkan Table 2 hasil analisis univariat dapat dilihat diatas. Bahwa sebagian besar responden mendapatkan Dakungan Sosial baik yaitu sebanyak 29 responden $(70,7)$.

\section{Distribusi Frekuensi Self-care Management Hipertensi}

Tabel 3 Distribusi Frekuensi Self-care Management Hipertensi di Puskesmas Sedayu II Bantul Yogyakarta

\begin{tabular}{lll}
\hline Self-care Management & $\begin{array}{l}\text { Frekuensi (f) } \\
\text { Persentas }\end{array}$ \\
\hline Kurang & 13 & 31,7 \\
\hline Baik & 28 & 69,3 \\
\hline Total & 41 & 100 \\
\hline
\end{tabular}

Berdasarkan Tabel 3 hasil analisis univariat dapat dilihat diatas. self-care management responden sebagian besar responden memiliki self-care management dengan kategori baik yaitu sebanyak 28 responden $(69,3 \%)$.
Tabel 4 Hubungan antara Dukungan Sosial dengan Self Care Management pada Lansia Hipertensi di Puskesmas Sedayu II Bantul Yogyakarta

\begin{tabular}{lllllll}
\hline & $\mathrm{f}$ & $\%$ & $\mathrm{f}$ & $\%$ & & \\
\hline Baik & 25 & $\begin{array}{l}61,4 \\
0\end{array}$ & 9,8 & 28 & 0,001 & 0,514 \\
\hline Kurang & 3 & 7,3 & 22,0 & 12 & \\
\hline Total & 28 & \multicolumn{6}{l}{68,13} & 31,7 & 41 & \\
\hline
\end{tabular}

Berdasarkan analisis Tabel 4 menunjukkan dari 41 lansia dapat dilihat bahwa respenden dengan dukungan sosial yang baik yaitu sebanyak 25 respenden $(61,0)$ dukungan sosial yang kurang memiliki selfcare management yang baik sebanyak 3 responden $(7,3 \%)$ sedangkan dukungan sosial yang baik memiliki self-care yang kurang yaitu sebanyak 4 responden $(9,8 \%)$ dukungan sosial yang kurang memiliki self-care management yang kurang sebesar 9 responden $(22,0 \%)$.

Hasil ini dapat diartikan bahwa ketika semakin baik dukungan sosial terhadap lansia maka akan semakin baik pula kemampuan self-care management pada lansia tersebut sebaliknya pula jika dukungan sosial kurang maka selfcare management kurang.

Berdasarkan hasil uji statistik dalam penelitian ini didapatkan hasil $p$-value adalah 
Dinamika Kesehatan Jurnal Kebidanan dan Keperawatan Vol 10 No. 22019 ( ISSN: 2086-3454 EISSN: 2549-4058) url: http://ojs.dinamikakesehatan.unism.ac.id DOI: https://doi.org/10.33859/dksm.v10i2

Dukungan Sosial Berhubungan Dengan Self-care Management Pada Lansia Hipertensi Di Puskesmas Sedayu II

0,000 lebih kecil dari $0,05(0,000<0,05)$, maka dapat dinyatakan hipotesis dalam penelitian ini diterima, yang berarti adanya hubungan antara dukungan sosial dengan self-care manegement pada lansia hipertensi di Puskesmas Sedayu II Bantul Yogyakarta. Sedangkan untuk keeratan hubungan didapatkan nilai koefisien korelasi sebesar 0,514 yaitu berada pada rentang kategori 0,40-0,599 yang berarti keeratan hubungan antara kedua variabel adalah sedang

\section{Pembahasan}

\section{Analisis Univariat}

\section{a. Distribusi Lansia Berdasarkan Usia}

Berdasarkan data yang didapatkan dalam penelitian ini hasil penelitian menunjukkan bahwa lansia yang terlibat dalam penelitian ini yang telah memenuhi kreteria inklusi maupun kreteria eksklusi berjumlah 41 responden. Distribusi lansia berdasarkan umur menunjukkan bahwa rata-rata lansia yang di jadikan responden berada pada rentang usia $<70$ tahun yaitu sebanyak 29 orang $(70,7 \%)$, sedangkan lansia yang berumur $>70$ tahun hanya terdapat 12 responden (29,3\%). Prevalensi lansia di Indonesia pada tahun 2020 diperkirakan akan mencapai jumlah sekitar 80 juta jiwa dan pada tahun 2012 yang lalu dari hasil susenas berdasarkan urutan provinsi paling tinggi presentase penduduk lansia diatas $10 \%$ yakni Yogyakarta yang menjadi salah satu provinsi dengan jumlah lansia tertinggi yakni mencapai $13,04 \%$ (3).

\section{b. Distribusi Lansia Berdasarkan Jenis Kelamin}

Hasil penelitian menunjukkan bahwa distribusi lansia berdasarkan jenis kelamin tabel 1 menunjukkan bahwa jumlah lansia perempuan sebanyak 23 responden $(56,1 \%)$. Hal ini menunjukkan bahwa lebih banyak perempuan dibandingkan dengan jumlah lakilaki yang hanya berjumlah 18 responden $(43,9)$. Menurut (9) berdasarkan penyebab terjadinya hipertensi jenis kelamin merupaka faktor resiko hipertensi yang tidak dapat dikontrol dimana perempuan lebih tinggi beresiko terjadi penyakit hipertensi dari pada laki-laki. Dimana pada wanita pasca menopause beresiko tinggi terkena hipertensi 
Dinamika Kesehatan Jurnal Kebidanan dan Keperawatan Vol 10 No. 22019 ( ISSN: 2086-3454 EISSN: 2549-4058) url: http://ojs.dinamikakesehatan.unism.ac.id DOI: https://doi.org/10.33859/dksm.v10i2

Dukungan Sosial Berhubungan Dengan Self-care Management Pada Lansia Hipertensi Di Puskesmas Sedayu II

yang menunjukkan adanya pengaruh hormon pada usia 45 tahun (17).

Hasil penelitian ini juga sejalan dengan hasil penelitian Ghani, Mihardja dan Delima dimana besar sampel perempuan sedikit lebih banyak dari laki-laki. Perempuan lebih cenderung mudah mengalami stres dan depresi yang diduga kuat menyebabkan resiko kematian perempuan lebih tinggi (54)

\section{c. Distribusi Lansia Berdasarkan Tingkat}

\section{Pendidikan}

Hasil penelitian menunjukkan bahwa distribusi lansia berdasarkan tingkat pendidikan berdasarkan tabel 1 menunjukkan bahwa sebagian besar lansia hanya lulusan SD yaitu sebanyak 17 responden $(41,5 \%)$, sedangkan untuk lulusan SMP sebanyak 8 responden $(19,5 \%)$ dan yang berpendidikan SMA yaitu sebanyak 5 responden (12,2\%), sedangkan yang Tidak Sekolah berjumlah 11 responden ( 26,8\%). Hal tersebut dikarenakan berdasarkan data yang didapat sebagian besar dari lansia berada pada ekonomi yang rendah sehingga lansia ini tidak dapat melanjutkan pendidikan yang lebih tinggi lagi.

\section{d. Distribusi Lansia Berdasarkan Pekerjaan}

Hasil penelitian menunjukkan bahwa distribusi lansia berdasarkan dengan pekerjaan menunjukkan bahwa lansia yang bekerja sebagai petani sebanyak 21 responden $(51,2 \%)$, lansia yang tidak bekerja sebanyak 11 responden $(26,8)$, lansia yang pekerjaan sebagai PNS sebanyak 3 responden (7,3\%), sedangkan lansia yang pekerja sebagai wiraswasta sebanyak 6 responden $(14,6 \%)$. Berdasarkan hasil diatas menunjukkan tingginya jumlah lansia yang masih bekerja dibandingkan dengan yang tidak bekerja. Sehingga dalam hal ini menunjukkan bahwa lansia tersebut tidak ingin menggantungkan hidupnya dengan anggota kelurga dan orang lain.

\section{e. Dukungan Sosial Lansia di Puskesmas Sedayu II Bantul Yogyakarta}

Hasil penelitian menunjukkan bahwa dukungan sosial berdasarkan tabel 2 dukungan sosial mayoritas dalam kategori baik yaitu sebanyak 29 responden $(70,7 \%)$ dan dukungan sosial dalam kategori kurang yaitu sebanyak 12 responden (29,3\%). Dukungan sosial merupakan bantuan dari orang lain yang 
Dinamika Kesehatan Jurnal Kebidanan dan Keperawatan Vol 10 No. 22019 ( ISSN: 2086-3454 EISSN: 2549-4058) url: http://ojs.dinamikakesehatan.unism.ac.id DOI: https://doi.org/10.33859/dksm.v10i2

Dukungan Sosial Berhubungan Dengan Self-care Management Pada Lansia Hipertensi Di Puskesmas Sedayu II

diberikan kepada seseorang sehingga dapat memudahkan seseorang dalam mencapai sesuatu yang dibutuhkannya, dukungan bisa dalam bentuk material dan juga bantuan moral, bisa dalam bentuk pemberian informasi baik secara verbal maupun informasi non verbal, pemberian bantuan dari orang lain atau yang didapat dari hubungan sosial dari teman, tetangga, keluarga (10).

Dalam hal ini penelitian ini sejalan dengan penelitian Nuniek Fajriah (14) dengan judul dukungan sosial pada pasien hipertensi dimana dari hasil penelitian menunjukkan pentingnya dukungan sosial pada pasien hipertensi sehingga dapat meningkatkan kesejahteraan kesehatan pada lansia. Menurut (11) dukungan yang diberikan dapat meningkatkan pengetahuan pada lansia dan menstabilkan emosional pada lansia hipertensi, dukungan itu dalam bentuk yaitu dukungan emosional, dukungan informasi, dukungan instrumental, dan dukungan penilaian.

\section{f. Self-care Management Hipertensi Lansia} di Puskesmas Sedayu II Bantul Yogyakarta Hasil penelitian ini menunjukkan bahwa selfcare management hipertensi berdasarkan tabel 3 self-care management hipertensi pada lansia mayoritas dalam kategori baik yaitu sebanyak 28 responden $(69,3 \%)$ dan self-care management hipertensi dalam kategori kurang yaitu 13 responden $(31,7 \%)$. Self-care Management merupakan suatu kemapuan seseorang dalam melakukan sesuatu secara mandiri, dalam melakukan aktivitas perawatan diri untuk mempertahankan kualitas hidup individu, individu mampu meningkatkan dan memelihara kesehatannya sehingga tercapainya kesejahteraan tingkat kesehatan yang optimal (13). Sehingga dalam hal ini pentingnya bagi lansia untuk mendapatkan dukungan sosial yang didapat dari keluarga, teman dan masyarakat agar lansia dapat menjalankan self-care mangement hipertensi dengan baik. Tetapi penelitian ini tidak sejalan atau bertolak belakang dengan hasil peneltian oleh Nurul Wahyu dengan judul hubungan antara dukungan keluarga dan self-care management pada lansia hipertensi di 
Dinamika Kesehatan Jurnal Kebidanan dan Keperawatan Vol 10 No. 22019 ( ISSN: 2086-3454 EISSN: 2549-4058) url: http://ojs.dinamikakesehatan.unism.ac.id DOI: https://doi.org/10.33859/dksm.v10i2

Dukungan Sosial Berhubungan Dengan Self-care Management Pada Lansia Hipertensi Di Puskesmas Sedayu II

Posyandu lansia di semarang, dari hasil penelitiannya tidak adanya hubungan (15).

\section{Analisis Bivariat}

a. Hubungan Dukungan Sosial dengan Self Care Management pada Lansia Hipertensi diPuskesmas Sedayu II Bantul Yogyakarta

Hasil penelitian penelitian menunjukkan bahwa dukungan sosial lansia Prolanis di Puskesmas Sedayu II Bantul Yogyakarta menunjukkan dari 41 lansia dapat dilihat bahwa respenden dengan dukungan sosial yang baik dan memliki self-care management yang baik yaitu sebanyak 25 respenden $(61,0)$ dukungan sosial yang kurang memiliki self-care management yang baik sebanyak 3 responden (7,3\%) sedangkan dukungan sosial yang baik memiliki self-care management yang kurang yaitu sebanyak 4 responden $(9,8 \%)$ dukungan sosial yang kurang memiliki self-care management yang kurang sebesar 9 responden $(22,0 \%)$. Hasil ini dapat diartikan bahwa ketika semakin baik dukungan sosial terhadap lansia maka akan semakin baik pula kemampuan self-care management pada lansia tersebut sebaliknya pula jika dukungan sosial kurang maka selfcare management kurang.

Berdasarkan hasil uji statistik Fisher's Exact Test dalam penelitian ini didapatkan hasil $p$-value adalah 0,000 , maka dapat dinyatakan hipotesis dalam penelitian ini diterima, yang berarti adanya hubungan antara dukungan sosial dengan self-care manegement pada lansia hipertensi di Puskesmas Sedayu II Bantul Yogyakarta. Sedangkan hasil Fisher's Exact Test untuk keeratan hubungan didapatkan nilai koefisien korelasi sebesar 0,514 yaitu berada pada rentang kategori 0,40 0,599 yang berarti keeratan hubungan antara kedua variabel adalah sedang. Hal ini menunjukkan dengan adanya dukungan sosial pada lansia hipertensi dapat memeberi pengaruh terhadap self-care management lansia lebih baik lagi.

Berdasarkan hasil penelitian disimpulkan bahwa semakin baik dukungan sosial yang didapatkan oleh lansia yang mengalami hipertensi maka akan semakin baik juga kemampuan menjalankan self-care management hipertensi. Dukungan sosial akan memberikan pengaruh terhadap tindakan 
Dinamika Kesehatan Jurnal Kebidanan dan Keperawatan Vol 10 No. 22019 ( ISSN: 2086-3454 EISSN: 2549-4058)

url: http://ojs.dinamikakesehatan.unism.ac.id DOI: https://doi.org/10.33859/dksm.v10i2

Dukungan Sosial Berhubungan Dengan Self-care Management Pada Lansia Hipertensi Di Puskesmas Sedayu II

serta pandangan lansia agar dapat melakukan self-care management dengan baik sehingga dapat meningkatkan kesejahteraan kesehatannya.

\section{UCAPAN TERIMA KASIH}

Puji syukur kita panjatkan kehadirat

Allah SWT karena dengan rahmat dan hidayah-nya sehingga penulis dapat menyelesaikan penelitian ini dengan judul "Hubungan Dukungan Sosial dengan Selfcare Management pada Lansia Hipertensi di Puskesmas Sedayu II Bantul

". Bimbingan, bantuan dan motivasi banyak penulis dapatkan dalam proses penyelesaian penelitian ini hingga akhirnya penulis mampu menyelesaikannya. Penulis mengucapkan banyak terima kasih kepada pihak-pihak yang telah membantu dalam penelitian ini.

Dalam kesempatan ini penulis mengucapkan terima kasih kepada :

1. Prof. Dr. H. Hamam Hadi, MS.Sc.D., Sp.GK selaku Rektor Universitas Alma Ata Yogyakarta.

2. Pihak Puskesmas Sedayu II Bantul atas bantuannya sehingga skripsi ini dapat terselesaikan.
3. Serta semua pihak yang tidak dapat penulis sebutkan satu per satu, terima kasih atas do'a, dan dukungannya.

Penulis menyadari bahwa dalam penelitian ini masih sangat jauh dai kesempurnaan. Oleh karena itu, penulis mengharapkan adanya kritik dan saran yang bersifat membangun sehingga dapat membantu menyempurnakan penelitian ini.

\section{DAFTAR PUSTAKA}

Vina, D.W dan Fitrah. Memahami Kesehatan Pada Lansia. Jakarta: CV. Trans Info Media: 2010.

Depsos RI. Dukungan Kelembagaan dalam Kerangka Peningkatan Kesehatan Lansia

(Kantor Urusan Pemberdayaan Lansia). Jakarta: Departemen Sosial RI. 2011.

BPS. Badan Pusat Statistik Kabupaten Bantul. Available from: www.bantulkab.bps,go.id:2014 Sustrani, L. Hipertensi. Jakarta: PT Gramedia Pustaka Umum: 2010.

Sustrani, L. Hipertensi. Jakarta: PT Gramedia Pustaka Umum: 2010.

Hendra Efendi, TA Larasati. Dukungan Sosial Dalam Manajemen Penyakit Hipertensi.

Kementerian Kesehatan R.I. Laporan Riset Kesehatan Dasar 2013. Jakarta: Kementerian R.I: 2014.

Dinkes Bantul. Profil Kesehatan Tahun 2015. Yogyakarta: Dinkes Bantul: 2015.

Ardiansyah, M. Medical Bedah untuk Mahasiswa. Yogyakarta: Diva press: 2012. 
Zaidin , H. Pengantar Keperawatan Keluarga. Jakarta: EGC. 2010.

Dewi, S. Rhoma. Buku Ajar Keperawatan Gerontik. Yogyakarta: Deepublish. 2014.

Indriani, H. Care Yaur Self Hipertensi. Jakarta: Penebar Plus. 2010.

Darmiati. Hubungan Dukungan Sosial Dengan Self-care Management Penderita Hipertensi Di Posbindu Desa Kalierang Kecamatan Selomerto Kabupaten Wonosobo. Universitas Ngudi Waluyo: 2017.

Fajriah, N. Dukungan Sosial Keluarga pada Pasien Hipetensi. 2016: Vol IX, No 2, September 2016. ISSN 1978-3167. Available

From: http://dowload.portalgaruda.org/article .php?article $=48189 \& \mathrm{val}=5468 \&$ title $=$ Dukungan $\% 20$ Sosial $\%$ Keluarga $\% 20 p$ ada $\% 20$ Pasien $\% 20$ Hipetensi

Wachyu, N. Hubungan Antara Dukungan Keluarga dan Self Care Management Lansia dengan Hipertensi di Posyandu Lansia Kelurahan Manyar Sabrangan Surabaya. 2014. Fakultas Keperawatan Universitas Airlangga. Available From:http:/journal.umpo.ac.id/index.p $\mathrm{hp} / \mathrm{IJHS} /$ article/view/725

Hidayanti, W. Pengalaman Self-care Berdasarkan Teori Orem pada Pasien Penyakit Ginjal Mengalami Hemodialisa [Skripsi]. Yogyakarta; Universitas Alma Ata; 2012.

Budi, S. Menu Sehat Penakluk Hipertensi. Jakarta: DeMedia. 2010.

Elizabet, L. Stop Merokok. Yogyakarta: Gara Ilmu: 2010.

Mahfud \& Eni Susani. Hubungan Perokok Berat dengan Kejadian Hipertensi. 2018.
Depkes RI. Pharmceutical Care Untuk Penyakit Hipertensi, Direktorat Bina Formasi Komunitas Dan Klinik. Jakarta: Ditjen Bina Kefarmasian Dan Alat Kesehatan. 2010.

Maryam, Set al, Mengenal dan Usia Lanjut dan Perawatannya. Jakarta: Selemba Medica. 2012.

Dwi Wahyunita Vina. Memahami Kesehatan Pada Lansia. Jakarta : TIM. 2012.

Setiadi. Konsep dan Penulisan Riset Keperawatan. Yogyakarta: Grahailmu. 2017.

Myers G, David. Psikologi Sosial Edisi 10. Penerbit Selemba Humanik: Jakarta. 2012.

Appolo, \& Cahyadi, A. Konflik Peran Ganda Perempuan Menikah yang Bekerja Ditinjau dari Dukungan Sosial dan Penyesuaian Diri. 2012.

Stanley dan Beare. Buku Ajar Keperawatan Gerontik. Jakarta: EGC. 2013

Cornwell, E.Y. Dan Wait, L.J. Networks And Support In Disiase Management Sosial An Examination. 2013.

Nwinee, J.P,. Nwinee Socio- Behavioral Self Care Management Nursing Model. West African Journal Of Nursing. 2014.

Hidayat AAA, MU. Pengantar Kebutuhan Dasar Manusia. 2 nd ed. Gnianjri Tu \& F, editor. Jakarta: Selemba Medika: 2014.

Nurjannah I. Pedoman Penangan Pada Gangguan Jiwa Yogyakarta: Moca Media. 2012.

Hidayat AAA. Pengantar Kebutuhan Dasar Manusia. I.st ed. Sjabena DD, editor. Jakarta: Selemba Medika: 2013. 
Viera, A.J., \& Jamision, B., How Effective Hipertension Self-care Intervention. 2012.

Santoso, D. Membonsai Hipertensi, PT. Tamprina Media Grafika: Surabaya. 2010.

Sutanto. Cekal Penyakit Modern Hipertensi, Stroke, Jantung, Kolestrol dan Diabetes, Ahdi, Yogyakarta. 2010.

Yugiantoro, Pranawa, Irwandim, C., Santoso, D,. Mardiana, N., Hipetensi, dalam Tjokroprawiro, A., Setiawan, P.B., Santoso, D., Sugianto, G. (ed), Buku Ajar Ilmu Penyakit Dalam, Airlangga University Press, Surabaya. 2014.

Almatsier, S,. Penuntut Diet, edisi baru, Instalasi Gizi Perjan RS Dr. Cipto Mangunkusumo dan Asosiasi Dietisen Indonesia, PT. Gramedia Pustaka Utama: Jakarta. 2013.

Tazim, V., Mc Connell, H., Gracon, S.L., Nursing Management for Hipertension. RNAO, Ontario. 2015.

Machfoedz, Ircham. Metodologi Penelitian. Yogyakarta: Fitramaya: 2014.

Notoatmojo, Soekidjo. Metodologi Penelitian Kesehatan. Jakarta: Rineka Cipta. 2012.

Sugiyono. Buku Statistika Untuk Penelitian Bandung: 2012.

Tilong. AD. Waspada Penyakit-penyakit Mematikan tanpa Gejala. Yogyakarta: Buku Biru. 2014.

Agus, Riyanto dan Budiman. Kapita Selekta Kuesioner Pengetahuan dan Sikap dalam

Penelitian Kesehatan. Jakarta: Salemba Medika. 2013.
Suryono. Metodologi Penelitian Kuantitatif \& Kualitatif dalam bidang kesehatan. Yogyakarta: Nuha Medika. 2013.

Machfoedz, Ircham. Metodologi Penelitian. Yogyakarta: Fitramaya: 2014.

Prasetyo, AS. Analisis Faktor-faktor yang Berhubungan dengan Self-care Management pada Asuhan Keperawatan Pasien Hipertensi di RSUD Kudus [internet]; 2012. Pakultas Ilmu Keperawatan. Available From:http://lib.ui.ac.id/file?file=digital /20307703-T31185 Analisis\%20faktor.pdf

Rosalind, M. Peters. Measuring Blood Pressure Knowledge and Self-Care Behaviors of African Amaricans; 2008. NIH Public Access

Arikunto. Prosedur Penelitian (Suatu Pendekatan Praktik). Jakarta: Rineka Cipta; 2013.

Machfoedz, Ircham. Metodologi Penelitian Kuantitatif \& Kualitatif. Yogyakarta: Fitramaya. 2016.

Nursalam. Metode Penelitian Ilmu Keperawatan: Pendekatan Praktis. Jakarta: Selemba Medika. 2014.

Sugiyono. Statistika Untuk Penelitian. Bandung: Alfabeta. 2011.

Machfoedz. Ircham. Bio Statistika. Yogyakarta: Fitramaya. 2015.

Sugiyono. Statistika Untuk Penelitian. Bandung: Alfabeta. 2011.

Machfoedz, Ircham. Metodologi Penelitian Kuantitatif \& Kualitatif. Yogyakarta: Fitramaya. 2016. 
Dinamika Kesehatan Jurnal Kebidanan dan Keperawatan Vol 10 No. 22019 ( ISSN: 2086-3454 EISSN: 2549-4058)

url: http://ojs.dinamikakesehatan.unism.ac.id DOI: https://doi.org/10.33859/dksm.v10i2

Dukungan Sosial Berhubungan Dengan Self-care Management Pada Lansia Hipertensi Di Puskesmas Sedayu II

Ghani, Lannywati; Mihardja, Laurentia; dan Delima. Faktor Resiko Dominan Penderita Stroke di Indonesia. Buletin Penelitian Kesehatan, Vol. 44, No. 1, Maret 2016 : 49-58. Jakarta: Puslitbang;2016.https:atauataumedia.n eliti.comataumediaataupublicationsata u20146-ID-faktor-risiko- dominanpenderita-stroke-di-indonesia.pdf.

Diakses Tanggal 14 Mei 2018 Jam 15.36 WIB

Zhong, X,. Awarnes and Practice of SelfManagement and influrnce factor among individuals with type 2 diabetes in urban community setting in Anhui Province, China. Institute of Health Education, Anhui Provincial Canter for Desease Control and Provention (AHCDC),42, 184-196. 2011. 